\title{
Culicoides paolae and C. circumscriptus as potential vectors of avian haemosporidians in an arid ecosystem
}

\author{
Jesús Veiga ${ }^{1 *}$ (D) Josué Martínez-de la Puente ${ }^{2,3}$, Radovan Václav ${ }^{4}$, Jordi Figuerolala ${ }^{2,3}$ and Francisco Valera ${ }^{1}$
}

\begin{abstract}
Background: Haemosporidians are the most important vector-borne parasites due to their cosmopolitan distribution and their wide range of hosts, including humans. Identification of their vectors is critical to highlight ecologically and epidemiologically relevant features such as host specificity or transmission routes. Biting midges of the genus Culicoides are considered the main vectors of Haemoproteus spp., yet important information on aspects such as vector feeding preferences or vector-host specificity involving haemosporidian parasites is frequently missing.

Methods: We assessed the abundance of Culicoides circumscriptus and C. paolae and blood sources of the latter at the nests of cavity-nesting bird species (mainly the European roller Coracias garrulus) and in their surroundings. We also explored the prevalence and genetic diversity of avian haemosporidians in parous females of both species.

Results: Both C. circumscriptus and C. paolae were abundant in the study area and common at European roller nests. Culicoides paolae had a diverse ornithophilic diet, feeding on at least seven bird species. Human DNA was also detected in the blood meal of some individuals. Four Haemoproteus lineages, including a new one reported here for the first time, were isolated from parous females of both biting midges.
\end{abstract}

Conclusions: Culicoides circumscriptus and C. paolae can play a locally important role in the transmission dynamics of Haemoproteus parasites in a community of cavity-nesting bird species in an arid ecosystem.

Keywords: Biting midges, Haemoproteus, Vector-borne, Arid area, Endophagy, Blood meal, Coracias garrulus

\section{Background}

Biting midges of the genus Culicoides are small, cosmopolitan blood-sucking insects playing an important role as vectors of numerous viruses, filarial nematodes and protozoa affecting human, livestock and wildlife [1, 2]. Culicoides are regarded as the main vectors of Haemoproteus (class Aconoidasida, order Haemosporidia, subgenus Parahaemoproteus) [3]. Still, they are the least studied of the major dipteran vector groups and our knowledge of their vectorial role is biased. On one side, their participation in the transmission of livestock and human viruses has received much attention (e.g. bluetongue virus [4], African horse sickness virus [5], Oropouche virus [6]). On the other side, much less is known

\footnotetext{
* Correspondence: jveiga@eeza.csic.es

1Departamento de Ecología Funcional y Evolutiva, Estación Experimental de Zonas Áridas (EEZA-CSIC), Ctra. de Sacramento s/n, La Cañada de San

Urbano, E-04120 Almería, Spain

Full list of author information is available at the end of the article
}

about their role in the transmission of avian haemosporidians. In particular, malaria-like parasites of the genus Haemoproteus are highly prevalent avian haemoparasites [7] with a relevant impact on the health status, longevity and fitness of their avian hosts [8-14]. Haemoproteus presents a high diversity in host-parasite associations [7] and it is unclear to what extent this diversity is due to host-parasite, host-vector or vector-parasite specificity [15-20]. Moreover, the vector identity and ecology of most Haemoproteus lineages is unknown [7, 21].

Tracing the feeding preferences (i.e. feeding patterns) of female Culicoides is critical to identify host-vector-parasite associations as well as ecologically and epidemiologically relevant features such as host specificity or transmission routes. Biting midges have a clear preference to feed mainly on either birds or mammals, with some species showing an opportunistic behaviour [22]. Traditionally, the feeding preferences of Culicoides have been assessed 
based on morphological characterization of the sensory structures (i.e. palps and antennae [23-25]). Other methods, such as the precipitin test [26-28], immunological assays $[29,30]$, and more recently, MALDI-TOF [31] and molecular tools [32, 33], have been applied to specifically identify the blood meal sources of female Culicoides and other insect vectors. Methods like the immunological assays are useful when the suitable hosts are suspected, which is commonly the case for the Culicoides surveys done in relation with livestock [34-37]. Yet, biting midges trapped in the wild may have a broad range of potential hosts, supporting the necessity to use approaches allowing the identification of a wide range of vertebrate species [22]. Studies on Culicoides feeding preferences in natural areas are especially scarce, although they provide a more complete view of the circulation of the blood parasites in the wild.

Here we studied the role of two common ornithophilic species of Culicoides in the transmission of avian haemosporidians in the driest European area, the Desert of Tabernas (south-eastern Spain). In this area, the prevalence of infection by Haemoproteus spp. varies between avian species, with a total absence of parasites found in adult Trumpeter finches (Bucanetes githagineus) while all the adult European rollers (Coracias garrulus) sampled showed evidence of infection [38, 39]. The haemosporidian species described for rollers in this area (Haemoproteus coraciae) was clustered, based on phylogenetic analysis, with other Haemoproteus spp. vectored by Culicoides [39], although the dipteran species involved in its transmission remains unidentified.

At least 81 species of the genus Culicoides are present in Spain [40]. In south-eastern Spain, different ornithophilic Culicoides species have been recorded including Culicoides paolae. This species, registered for first time in Spain in 2008 [41], has been frequently associated with livestock farms [34, 42, 43]. However, analysis of the sensory structures suggests an ornithophilic preference in this species [44], although the host sources of blood remain unidentified, and its role for the transmission of avian haemosporidians is completely unknown. This contrasts with other well-known, sympatric ornithophilic species such as $C$. circumscriptus, a common species in southern Spain which may be involved in the transmission of Haemoproteus parasites [18, 45, 46].

To assess the potential of C. paolae and C. circumscriptus as the vectors of blood parasites in a community of birds in south-eastern Spain we: (i) collected the specimens of the two species inside and in the surroundings of the nests of the European roller, one of the locally most abundant troglodytic species; (ii) identified the blood meal sources of engorged females; and (iii) studied the prevalence and genetic diversity of Haemoproteus parasites harboured by parous biting midge females.

\section{Methods}

\section{Study area}

This study was performed in an approximately $50 \mathrm{~km}^{2}$ area located in the Desert of Tabernas (Almería, SE Spain, $37^{\circ}$ $\left.05^{\prime} \mathrm{N}, 2^{\circ} 21^{\prime} \mathrm{W}\right)$. The landscape mostly consists of open shrubland with olive and almond groves interspersed among numerous dry riverbeds (ramblas). Inhabited farms are scarce and scattered along the study area. The climate is temperate, semiarid Mediterranean with a strong water deficit during the long, hot summer months (June to September), when the absolute maximum monthly temperature is higher than $40{ }^{\circ} \mathrm{C}$ and the monthly average of the maximum daily temperatures remains above $30{ }^{\circ} \mathrm{C}$ [47]. The average annual temperature is $18{ }^{\circ} \mathrm{C}$, with mild inter-annual oscillations of $3-4{ }^{\circ} \mathrm{C}$ and significant intra-annual fluctuations [47]. The mean annual rainfall is $c .230 \mathrm{~mm}$ with high inter-annual and intra-annual variability [48].

The bird community comprises species that breed mainly in cavities in the study area (e.g. the little owl Athene noctua, scops owl Otus scops, Eurasian jackdaw Corvus monedula, common kestrel Falco tinnunculus and feral pigeon Columba livia), chiefly in natural holes in sandy cliffs but also in cavities in human constructions [49]. The European roller (hereafter roller) is a common breeding species in the study area where it is distributed patchily according to distinct geomorphological units [50]: (i) ramblas (dry stream channels with steep sandstone banks), which are linear, continuous geographical units separated from neighbouring ramblas by hills and human settlements; (ii) individual bridges with numerous, densely spaced cavities (c.2-3 m apart); and (iii) spatial aggregations of suitable nesting places, mostly trees with nest boxes but also small sandstone banks with natural cavities and isolated country houses with cavities. Wooden nest boxes have been placed in these habitat types and most rollers individuals are currently breeding in them (height $\times$ length $\times$ width: $310 \times$ $232 \times 230 \mathrm{~mm}$, entrance diameter: $60 \mathrm{~mm}$, with a removable upper lid to allow nest monitoring) installed on isolated eucalyptus trees, sandstone banks and isolated and deserted country houses $[49,50]$. Rollers are migratory birds wintering in Africa and arriving at the breeding grounds in the study area when resident, secondary cavity-nesting birds are already settled. Eggs (mean clutch size $=4.23$ ) [51] are incubated by both sexes [52] during $c .21$ days. Rollers rear a single brood per year [52] with fledglings leaving the nest approximately 20 22 days after hatching in the studied population [50].

\section{Culicoides trapping}

Culicoides spp. specimens were trapped using two methods: sticky traps and CDC light traps. Sticky traps were placed in nest boxes occupied by rollers during the 2016 and 2017 breeding seasons (from 18 May to 4 July 
in 2016 and from 2 June to 18 July in 2017). Specifically, sticky traps were fixed under the upper lid of 69 nest boxes (32 in 2016 and 37 in 2017). In 2016 we took advantage of a pair of kestrels breeding in a next box close to a breeding pair of rollers, thus resembling natural nesting conditions with different cavity nesting bird species breeding in close proximity [50]. We followed the method described by Tomás et al. [53] (i.e using Petri dishes smeared with body gel-oil as a non-attractant glue) but replacing Petri dishes by white vegetal papers that were fixed by thumbtacks on the inner side of the upper lid. In 2016, these sticky traps $\left(\right.$ size $=63.6 \mathrm{~cm}^{2}$ ) were kept for three days in two periods of the breeding cycle: (i) at the end of the incubation phase (18-20 days after the first egg was laid); and (ii) during the nestling phase, when all chicks had already hatched (13-15 days after the first egg hatched). In 2017, sticky traps were only placed during the nestling stage, because most vectors were captured during this stage in 2016, and the trap size was increased (size $=175.5 \mathrm{~cm}^{2}$ ). Thus, in 2017, a first trap was set 13 days after the first egg hatched and kept for four days. Then, it was replaced by a new trap that was kept for a second period of four days. Additionally, opportunistic catches of Culicoides at the nests were made by hand during routine visits.

Additionally, CDC traps were set throughout the study area during 2016 and 2017. We used traps with UV light as they are recommended to attract Culicoides [54]. Moreover, since this study is part of a broader one aimed at studying the community of dipteran vectors, we also used incandescent light traps. Both trap types were put together and were also baited with $\mathrm{CO}_{2}$ in order to use as many different stimuli as possible. Dry ice was used as source of $\mathrm{CO}_{2}(1 \mathrm{~kg}$ of dry ice per night and pair of traps to ensure the continued emission of $\mathrm{CO}_{2}$ until the collection of the traps at dawn). Thus, 20 pairs of CDC traps (each pair formed by one trap with incandescent light and one with UV light, $c .50 \mathrm{~cm}$ apart from each other, both baited with $\mathrm{CO}_{2}$ ) were set all over the study area and in the main breeding habitats of the roller, namely trees, ramblas and bridges (see above), so that eight traps were located on ramblas, eight on trees and four on bridges during 2016 and 2017. The traps were powered by a $6 \mathrm{~V}$ battery of $12 \mathrm{Ah}$. The trapping sessions were adjusted according to the breeding season of rollers and the moon calendar, so that traps were active on the days during or close to the period of the new moon (reducing the effect of ambient light [55]), and avoiding windy nights. In 2016 we placed one group of 10 pairs of traps from 8 June to 10 June and a second group of 10 trap pairs from 7 July to 8 July. In 2017, all 20 trap pairs were set from 22 June to 1 July. Most traps $(82.5 \%)$ were set before dusk or shortly after and were removed after sunrise. Captured insects were moved to the Estación Experimental de Zonas Áridas and frozen in $70 \%$ ethanol until identification.

\section{Morphological identification}

Biting midges were identified to the species level based on González \& Goldarazena [56] and Mathieu et al. [57] taxonomic keys under a Zeiss Discovery V8 stereomicroscope. Culicoides circumscriptus and C. paolae were the most abundant biting midges at the nests (see Results), and individuals of these species collected at the nests and with CDC light traps were analysed for blood meal origin (engorged females) or Haemoproteus detection (parous females). Engorged females were identified based on the presence of blood remains in the abdomen. The abdomen of each C. paolae engorged female was separated from the head-thorax using sterile tips on chilly Petri dishes and, subsequently, maintained in individual vials. Diet analyses were restricted to C. paolae as only two engorged C. circumscriptus females were captured. Parous females were identified based on the presence of burgundy-red pigmented abdomen that develops during the first gonotrophic cycle [58]. As previous studies have reported a low prevalence of avian haemosporidians in Culicoides from southern Spain ([46], our unpublished observations], parous females were grouped in pools from 1 to 11 individuals according to species, date and site of capture.

\section{DNA extraction and molecular analyses}

Genomic DNA from the abdomen of each engorged $C$. paolae females and biting midge pools was extracted using the DNeasy Blood and Tissue ${ }^{\circ}$ kit (Qiagen, Hilden, Germany) following company specifications. Negative controls (reagents without a template) were used to detect possible contaminations. DNA was stored at $-20{ }^{\circ} \mathrm{C}$ until PCR amplification. To confirm the morphological identification of Culicoides species, we amplified a 658 base pair (bp) fragment of the mitochondrial cytochrome $c$ oxidase 1 ( $\operatorname{cox} 1$ gene, barcoding region) of four individuals following Gutiérrez-López et al. [59]. The vertebrate hosts of Culicoides females were identified by amplification of a fragment of $758 \mathrm{bp}$ of the vertebrate cox 1 gene following Alcaide et al. [32]. Finally, the presence and identity of Haemoproteus and Plasmodium spp. were assessed for the pools of parous female Culicoides specimens using the protocol by Hellgren et al. [60]. Parasite determination was conducted at least twice per sample to avoid false negative results [61]. The presence of amplicons was verified on $1.8 \%$ agarose gels. Positive amplifications were sequenced using the Macrogen laboratories sequencing service (Madrid, Spain) and sequences were edited using the software Sequencher ${ }^{\mathrm{Tm}}$ v.4.9 (Gene Codes Corp, Ann Arbor, MI, USA). 
The identity of Culicoides species and their vertebrate hosts were established by comparison with sequences deposited in GenBank DNA sequence database (National Center for Biotechnology Information BLAST) or the Barcode of Life Data Systems (BOLD). The molecular identification of two female $C$. paolae and two female $C$. circumscriptus confirmed the morphological identifications. Vertebrate species were confirmed if agreement was $\geq 98 \%$ with deposited sequences. Parasite lineages and morphospecies were identified by BLAST comparison with the sequences available in GenBank and MalAvi [62].

\section{Statistical analyses}

The abundance of parous $C$. paolae and C. circumscriptus captured in CDC traps were analysed with a generalized linear mixed model (GLMM) with the negative binomial distribution of errors. Year (2016 and 2017) and biting midge species were included as independent variables. Scaled and centred date of sampling was included in a GLMM as a covariate. The number (log-transformed, scaled and centred) of blood-feeding parasitic dipterans captured per pair of traps was included as an offset variable to correct for their abundance in each sampling point. Trap location, identical during both years, was included as a random factor. The interaction between sampling date and Culicoides species was introduced to explore a seasonal effect in the capture of the two species. One outlier due to the capture of 94 parous $C$. paoale was detected and the analyses were run with and without this datum. Given that the results obtained were qualitatively comparable, we report the analysis including this datapoint.

The prevalence of Haemoproteus spp. in Culicoides pools was estimated considering variable pool sizes and $100 \%$ test specificity and sensitivity following Sergeant [63]. Statistical analyses were performed using the R environment [64] with the lme4 and effects packages [65, 66].

\section{Results}

Abundance of Culicoides spp. in avian nests

Overall, 57 Culicoides spp. were collected in avian nest during both years $(n=42$ in 2016 and $n=15$ in 2017, Table 1). From the 57 captures, four individuals were collected opportunistically in the nest and 53 were collected by sticky traps. In addition, Simuliidae $(n=230)$ and Phlebotominae $(n=105)$ were other blood-feeding dipterans collected with the sticky traps at the nests.

The most abundant biting midges were $C$. paolae (57.9\%, 33 out of 57) and C. circumscriptus (22.8\%, 13 out of 57). Twenty-seven C. paolae specimens were parous and six were engorged, whereas $11 \mathrm{C}$. circumscriptus specimens were parous, two nulliparous (not included in Table 1) and no engorged individual was captured. Twenty-two out of the 32 C. paolae collected in 2016 were captured in a common kestrel nest.

\section{Abundance of Culicoides spp. in CDC traps}

Overall, 7764 Culicoides spp. were captured using CDC traps (Table 1). Of them, 341 were parous females of $C$. paolae and $C$. circumscriptus, representing $4.4 \%$ of the

Table 1 Abundance, mean \pm SD, and range (in parentheses) for Culicoides spp. (overall data set) and for the subset of parous and engorged females of C. paolae and C. circumscriptus trapped in avian nests and their surroundings during 2016 and 2017

\begin{tabular}{|c|c|c|c|c|}
\hline & \multicolumn{2}{|l|}{ Inside nest } & \multicolumn{2}{|l|}{ Outside nest } \\
\hline & 2016 ( $n=33^{\mathrm{a}}$ nests) & $2017(n=37$ nests $)$ & $2016(n=20$ trap pairs $)$ & $2017(n=20$ trap pairs $)$ \\
\hline \multirow[t]{3}{*}{ Culicoides spp. } & 42 & 15 & 3585 & 4179 \\
\hline & $1.27 \pm 4.38$ & $0.41 \pm 0.90$ & $179.25 \pm 160.77$ & $208.95 \pm 187.31$ \\
\hline & $(0-25)$ & $(0-4)$ & $(0-423)$ & $(2-380)$ \\
\hline \multirow[t]{3}{*}{ C. paolae parous } & 26 & 1 & 77 & 180 \\
\hline & $0.79 \pm 3.56$ & $0.03 \pm 0.164$ & $3.85 \pm 6.79$ & $9 \pm 20.59$ \\
\hline & $(0-20)$ & $(0-1)$ & $(0-27)$ & $(0-94)$ \\
\hline \multirow[t]{3}{*}{ C. circumscriptus parous } & 3 & 8 & 34 & 50 \\
\hline & $0.09 \pm 0.29$ & $0.22 \pm 0.75$ & $1.70 \pm 3.42$ & $2.5 \pm 3.01$ \\
\hline & $(0-1)$ & $(0-4)$ & $(0-15)$ & $(0-11)$ \\
\hline \multirow[t]{3}{*}{ C. paolae engorged } & 6 & 0 & 14 & 16 \\
\hline & $0.18 \pm 0.58$ & & $0.7 \pm 0.92$ & $0.8 \pm 1.06$ \\
\hline & $(0-2)$ & & $(0-3)$ & $(0-3)$ \\
\hline \multirow[t]{3}{*}{ C. circumscriptus engorged } & 0 & 0 & 0 & 2 \\
\hline & & & & $0.1 \pm 0.45$ \\
\hline & & & & $(0-2)$ \\
\hline
\end{tabular}


total Culicoides spp. specimens captured (Table 1). The average number of parous females per pair of traps was 3.8 of C. paolae and 1.7 of C. circumscriptus in 2016 and 9 of C. paolae and 2.5 of C. circumscriptus in 2017. Furthermore, 30 engorged females of C. paolae and two engorged females of $C$. circumscriptus were also captured (Table 1).

The abundance of parous biting midges (C. paolae and C. circumscriptus) was greater in 2017 and decreased through the breeding season. Culicoides paolae was significantly more abundant than $C$. circumscriptus (Table 2). The interaction between Culicoides species and sampling date was also significant (Table 2), because parous C. paolae was more abundant late in the roller breeding season and parous $C$. circumscriptus was more abundant early in the season (Fig. 1).

\section{Culicoides paolae feeding patterns}

Blood meals of 21 (58.3\%) out of the 36 engorged $C$. paolae were successfully identified. Of them, the six females captured in avian nests fed on the species breeding in these nest boxes (two on common kestrels and four on rollers) (Table 3). Culicoides paolae females captured with CDC traps $(n=15)$ fed mainly on birds (66.7\% of the identified blood meals) corresponding to five different species including cavity-nesting and open-nesting species. Finally, human DNA was found in five (33.3\%) out of 15 C. paolae collected with CDC traps (Table 3).

Prevalence and identification of haemosporidian parasites The prevalence of Haemoproteus spp. was 4.4\% (95\% CI: $1.39-9.95 \%, n=95$ individuals) and 0.7\% (95\% CI: 0.12$2.21 \%, n=284$ individuals) for $C$. circumscriptus and $C$. paolae pools, respectively. Overall, four Haemoproteus and one Plasmodium lineages were found. Of them, the three Hemoproteus lineages, TURDUS2, GAGLA03 (= GAGLA05, both sequences with equal coverage and identity) and AEFUN03, and the Plasmodium lineage SYAT05 (Plasmodium vaughani), were identified with $100 \%$ coverage and identity. The three Haemoproteus lineages, TURDUS2, GAGLA03 (=GAGLA05) and

Table 2 Results of a generalised mixed model analysing the abundance of parous Culicoides paolae and C. circumscriptus collected using CDC traps in relation to year $(2016,2017)$, date of capture, and the interaction between date of capture and the species of Culicoides biting midges

\begin{tabular}{lllll}
\hline Fixed effects & Estimate & SE & $z$-value & $P$ \\
\hline Intercept & 0.043 & 0.28 & 0.16 & 0.88 \\
Species (C. paolae) & 0.64 & 0.29 & 2.26 & 0.024 \\
Date & -0.63 & 0.23 & -2.71 & 0.007 \\
Year (2017) & 0.56 & 0.29 & 1.92 & 0.053 \\
Species (C. paolae)*Date & 1.10 & 0.31 & 3.57 & 0.0004 \\
\hline
\end{tabular}

AEFUN03, were isolated from C. circumscriptus specimens (Table 4). The Haemoproteus lineage TURDUS2 and the Plasmodium lineage SYAT05 were isolated from C. paolae specimens (Table 4). In addition, a new lineage (CUPAO-01, GenBank: MH237967) was isolated from a C. paolae specimen. This lineage showed $93 \%$ overlap and $99 \%$ similarity with the Haemoproteus coraciae lineage H1CG.1 (GenBank: KU297278) (Table 4). In fact, six nucleotide bases differed between both lineages.

\section{Discussion}

This study reveals that C. circumscriptus and C. paolae are common endophagous insects at the nests of cavity-nesting species, with $C$. paolae being identified for the first time, using identification of blood meals, as a potential vector of avian haemosporidians. This assertion is supported by detecting a high diversity of avian hosts including cavity-nesting and open-nesting species and the identification of avian haemosporidian parasites for C. paolae.

Whereas C. circumscriptus is common in Spain [56, 67-72], C. paolae was detected for the first time in 2008 [41]. It has been proposed that the latter species was introduced into Europe by Columbus's travels from America five centuries ago [44, 73]. In spite of some morphological differences, C. paolae is very similar to the American Culicoides jamaicensis [44] and a recent phylogenetic study related the former species with Culicoides from the New World [73]. Nowadays, in addition to Spain, where C. paolae is currently expanding its distribution range [41], this biting midge is the most widespread and abundant species of all Culicoides in Malta [34] and one of the most abundant species in central Tunisia [74] and Sardinia [75], where its importance on the local transmission of avian vector-borne pathogens should be considered. Culicoides paolae is commonly found near livestock farms [34, 74, 75], but according to our results, this species may also be widespread in the wild and, at least for the study period, it is even more abundant than C. circumscriptus (Tables 1,2). Data from two breeding seasons suggest that the two species exhibit different phenologies, C. paolae being more abundant late in the roller breeding season whereas the opposite is true for C. circumscriptus. Furthermore, whereas the ability of some ornithophilic biting midges to feed inside enclosed places (endophagy) has been previously shown $[39,53,69,76]$, to our knowledge this is the first time that endophagy has been recorded for C. paolae.

Culicoides paolae is defined as ornithophilic according to its sensory structures [44]. Here we provide for the first time, unequivocal identification of its hosts, including seven different bird species within the study area. This broad spectrum of hosts has already been described for other ornithophilic Culicoides species [22, 77]. 
Taxon versus Date

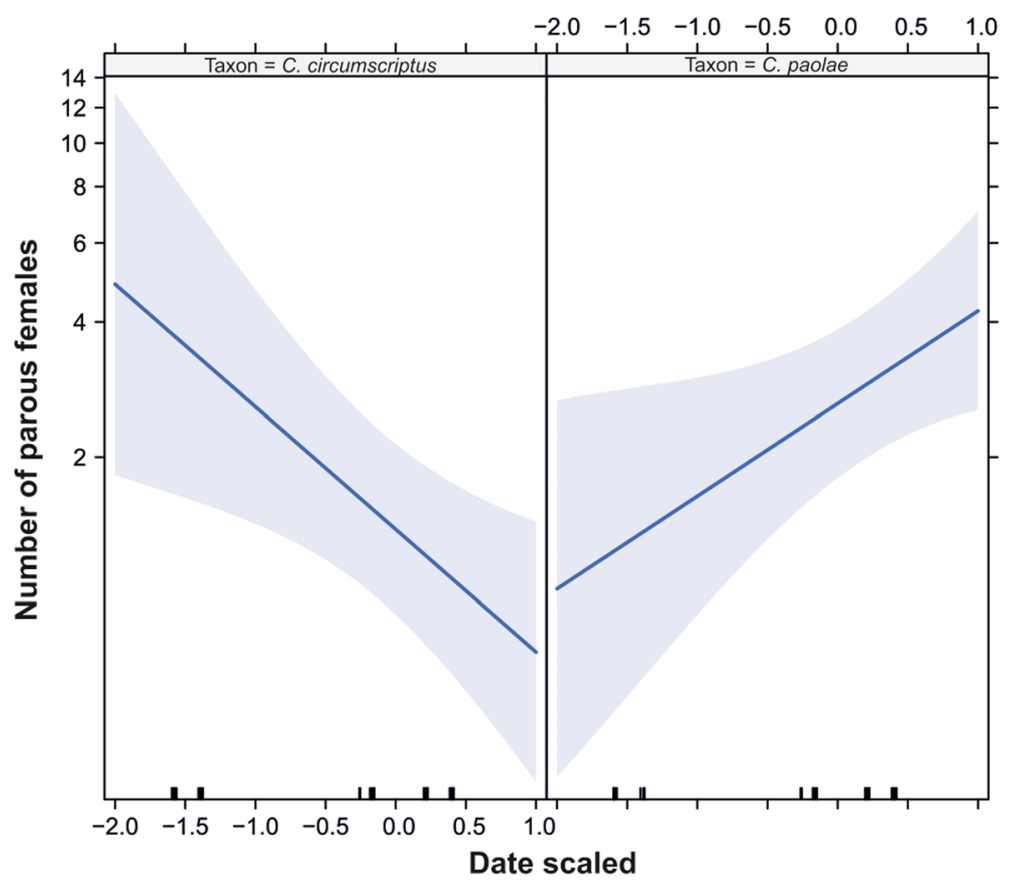

Fig. 1 Relationship between capture date and abundance of parous females of Culicoides circumscriptus (estimate $\pm S E=-0.63 \pm 0.23, P<0.01$ ) and $C$. paolae (estimate $\pm \mathrm{SE}=0.48 \pm 0.21, P=0.022$ ) captured with CDC traps in south-eastern Spain during 2016 and 2017. Date of capture was scaled and centred. Lines represent fitted values with shaded regions showing areas delimited by $95 \%$ confidence intervals

Interestingly, some of the host species are not particularly abundant in the study area, suggesting a remarkable feeding range of this biting midge and excellent host-searching abilities. Nonetheless, a greater effort in sampling engorged females C. paolae together with an analysis of the bird community composition around the traps is still necessary for a better knowledge of host selection by this dipteran. Our results also suggest that $C$. paolae could feed on humans. Even though we tried to minimize the risk of contamination, we did not type the human-positive samples with DNA samples of the experimenters (e.g. [78]). Thus, we cannot discard the possibility of sample contamination. Nonetheless, other ornithophilic species like C. kibunensis
[79, 80], C. circumscriptus [81], or C. pictipennis [82], have previously been reported to feed on humans. The broad range of hosts could help biting midges to face environmental changes [79], and in our case, it could have facilitated the establishment of $C$. paolae in a new area.

DNA from four Haemoproteus lineages and one Plasmodium lineage was detected in parous C. paolae and C. circumscriptus. Even though multiple Plasmodium lineages have been molecularly detected in Culicoides $[18,46]$, this does not imply vector competence [83]. Plasmodium is mainly transmitted by Culex mosquitoes [7] and our result could simply reflect the presence of abortive stages of $P$. vaughani in C. paolae [84].

Table 3 Hosts of C. paolae based on the molecular identification of blood meal origin. The number of successfully identified blood meals is shown for each species

\begin{tabular}{llll}
\hline & Host & Cavity/open nester & No. of successful amplifications \\
\hline Inside nests & European roller (Coracias garrulus) & 4 \\
& Common kestrel (Falco tinnunculus) & Cavity nester & 2 \\
CDC traps & Humans (Homo sapiens) & Cavity nester & 5 \\
& House sparrow (Passer domesticus) & Cavity nester & 4 \\
& Common blackbird (Turdus merula) & Open nester & 3 \\
& Eurasian hoopoe (Upupa epops) & Cavity nester & 1 \\
& Eurasian collared dove (Streptopelia decaocto) & Open nester & 1
\end{tabular}

The blood in the abdomen of the biting midge belonged to the avian species breeding at the nest where the biting midge was collected 
Table 4 Molecular identification of haemosporidians in pools of parous C. circumscriptus and C. paolae females trapped in avian nests and surroundings. Lineages and accession numbers from GenBank sequences showing the highest percentage of coverage and identity to those found in this study are shown. Previous information regarding these sequences is reported including the parasite morphospecies (when described), avian hosts and potential insect vectors (in bold) according to information of the reported sequences

\begin{tabular}{|c|c|c|c|c|c|}
\hline Pool code & Host in this study & $\begin{array}{l}\text { Closest lineages } \\
\text { (morphospecies) }\end{array}$ & GenBank ID & $\begin{array}{l}\text { Potential avian hosts } \\
\text { and vectors described }\end{array}$ & Coverage/identity (\%) \\
\hline $\begin{array}{l}\text { N7c35 } \\
\text { (Accession no.: MH237967) }\end{array}$ & C. paolae & $\begin{array}{l}\text { H1CG.1 } \\
\text { (Haemoproteus coraciae) }\end{array}$ & KU297278 & C. garrulus & $93 / 99$ \\
\hline $\begin{array}{l}\mathrm{N} 26 \mathrm{Cl} \\
\mathrm{NFCl}\end{array}$ & $\begin{array}{l}\text { C. circumscriptus } \\
\text { C. paolae }\end{array}$ & $\begin{array}{l}\text { Turdus2 } \\
\text { (H. minutus) }\end{array}$ & $\begin{array}{l}\text { MF625183 } \\
\text { KM361485 } \\
\text { KJ488583 } \\
\text { KC818452 } \\
\text { JN819398 } \\
\text { JN819388 } \\
\text { JN819383 } \\
\text { HQ398208 } \\
\text { DQ630013 } \\
\text { DQ060772 }\end{array}$ & $\begin{array}{l}\text { E. rubecula } \\
\text { G. glandarius } \\
\text { M. striata } \\
\text { T. merula } \\
\text { T. assimilis } \\
\text { T. icterocephala } \\
\text { B. lineola }\end{array}$ & $100 / 100$ \\
\hline $\begin{array}{l}\mathrm{NEC3} \\
\mathrm{NEC4}\end{array}$ & C. circumscriptus & $\begin{array}{l}\text { GAGLA05 } \\
\text { GAGLA03 } \\
\text { (Haemoproteus sp.) }\end{array}$ & $\begin{array}{l}\text { KX831071 } \\
\text { KJ488735 } \\
\text { GU085197 } \\
\text { MF594402 } \\
\text { MF095639 }\end{array}$ & $\begin{array}{l}\text { G. glandarius } \\
\text { C. circumscriptus }\end{array}$ & $100 / 100$ \\
\hline AGALM4 & C. circumscriptus & $\begin{array}{l}\text { AEFUN03 } \\
\text { (Haemoproteus sp.) }\end{array}$ & KP715101 & A. funereus & $100 / 100$ \\
\hline N31c2 & C. paolae & $\begin{array}{l}\text { SYAT05 } \\
\text { (Plasmodium vaughani) }\end{array}$ & $\begin{array}{l}\text { MF817773 } \\
\text { MF347700 } \\
\text { KJ488789 } \\
\text { JF411406 } \\
\text { AB477124 } \\
\text { DQ847271 }\end{array}$ & $\begin{array}{l}\text { C. caeruleus } \\
\text { S. maurus } \\
\text { S. unicolor } \\
\text { S. atricapilla } \\
\text { T. merula } \\
\text { T. migratorius } \\
\text { T. philomelos } \\
\text { T. viscivorus } \\
\text { C. pipiens }\end{array}$ & $100 / 100$ \\
\hline
\end{tabular}

We isolated four different Haemoproteus lineages from six pools of Culicoides females. A lineage of $H$. minutus (TURDUS2) was detected both in C. paolae and C. circumscriptus. This is a geographically widespread lineage (northwest Africa, northwest Iberia, Transcaucasia and western Greater Caucasus) infecting different avian species, with Turdus merula probably playing a central role as reservoir [85]. Additionally, GAGLA03 (=GAGLA05) was previously isolated in Bulgaria from Garrulus glandarius [86], C. circumscriptus in Spain ([46], this study) and Turkey (GenBank: MF594402 and MF095639). The lineage AEFUN03 that had been only detected previously in Aegolious funereus [87] was found in C. circumscriptus in south-eastern Spain. This bird species is absent from the study area and probably this Haemoproteus lineage is infecting another locally abundant owl (e.g. little owl Athene noctua). Finally, we also detected a new Haemoproteus lineage highly similar (99\% similarity) to the one corresponding to the haplotype H1CG.1 (identified as $H$. coraciae), which was detected previously in the same roller breeding population by Václav et al. [39]. Microscopic examination of smears suggested that this lineage might correspond to the species Haemoproteus coraciae [39], a parasite identified in rollers in
Bulgaria [88] and Kazakhstan [89]. For the case of avian malaria parasites and related haemosporidians, different lineages are described with differences of a single nucleotide base in their sequences [62]. However, different lineages showing few differences may correspond to the same parasite morphospecies. Thus, it is likely that the new lineage reported here (H1CG.1) corresponds to the $H$. coraciae morphospecies. Further analyses are necessary to confirm this possibility. Haemoproteus coraciae were widely prevalent in adult rollers and also present in nestlings, suggesting the presence of a competent vector in the breeding area [39]. Václav et al. [39] pointed out that the detection of a Haemoproteus species only infecting adult rollers was intriguing because all the Culicoides species studied by Bobeva et al. [82] were feeding on a wide range of avian host. Our results suggest that $C$. paolae may be a competent vector for $H$. coraciae probably playing a role on the transmission of locally circulating parasites that could be amplified by the migratory behaviour of rollers. Further analyses are necessary to confirm the vector competence of this Culicoides species for the transmission of the lineages isolated here [83].

The prevalence of Haemoproteus in C. circumscriptus in the study area (4.4\%) is slightly lower than the one 
observed in central Spain (16.7\% [18]) and southwestern Spain $(10.3 \%$ [46]), yet it is higher than the prevalence found in the sympatric C. paolae (0.7 vs 4.4\%). On the other hand, C. paolae is seemingly locally more abundant than C. circumscriptus both at the nests and in their surroundings. Therefore, both species could play an important role in the transmission dynamics of haemosporidian parasites in the study area. Nevertheless, other factors such as the efficiency of parasite transmission or seasonality in vector abundance should be considered. Concerning the latter, our study reveals that differential exposure of the hosts to individual biting midge species along the season is worth studying to fully understand the risk of haemosporidian transmission by each species.

\section{Conclusions}

Vectors for most haemosporidians are unidentified $[7,90]$ and thus parasite-vector associations remain an enigmatic aspect of haemosporidian parasite ecology $[17,19,91]$. Here, we provide valuable information about the Haemoproteus lineages potentially transmitted by two biting midges species. Culicoides paolae and C. circumscriptus were abundant both at the nests of cavity bird species and in their surroundings, with seasonal differences in abundance during the study period. We assessed the ornithophilic diet of $C$. paolae that fed on at least seven bird species and possibly also on humans. Both biting midge species harboured several Haemoproteus lineages. These findings provide an important first step towards the identification of $C$. paolae and C. circumscriptus as potential vectors of avian haemosporidian parasites.

\section{Abbreviations \\ MALDI-TOF: matrix-assisted laser desorption/ionization time-of-flight mass spectrometry; CDC: Centers for Disease Control; GLMM: Generalized linear} mixed effects models

\section{Acknowledgements \\ Francisco Collantes provided helpful advice concerning trapping methods. Domingo Álvarez, Isabel Martín and Laura Gómez helped in the laboratory analyses.}

\section{Funding}

JV was funded by the Spanish Ministry of Economy, Industry and

Competitiveness by means of a predoctoral grant (grant no. BES-2015-075951). FV and JF received financial support from the Spanish Ministry of Economy and Competitiveness, and the European Regional Development Fund (CGL201455969-P; CGL2015-65055-P). JMP was partially supported by a 2017 Leonardo Grant for Researchers and Cultural Creators, BBVA Foundation. The Foundation accepts no responsibility for the opinions, statements and contents included in the project and/or the results thereof, which are entirely the responsibility of the authors. We acknowledge support of the publication fees by the CSIC Open Access Publication Support Initiative through its Unit of Information Resources for Research (URICI).

\section{Availability of data and materials}

The datasets used and/or analysed during the current study are available from the corresponding author upon reasonable request. The new lineage sequence of $\mathrm{H}$. coraciae was submitted to the GenBank database under the accession number $\mathrm{MH} 237967$.

\section{Authors' contributions}

Conceived and designed the experiments: JV, RV and FV. Fieldwork: JV and FV. Contributed reagents/materials/analysis tools: JV, JMP, JF and FV. All authors contributed toward writing the manuscript. All authors read and approved the final manuscript.

\section{Ethics approval}

Bird trapping was carried out with all the necessary permits issued by the Junta de Andalucía.

\section{Consent for publication}

Not applicable.

\section{Competing interests}

The authors declare that they have no competing interests.

\section{Publisher's Note}

Springer Nature remains neutral with regard to jurisdictional claims in published maps and institutional affiliations.

\section{Author details}

${ }^{1}$ Departamento de Ecología Funcional y Evolutiva, Estación Experimental de Zonas Áridas (EEZA-CSIC), Ctra. de Sacramento s/n, La Cañada de San Urbano, E-04120 Almería, Spain. 'Departamento de Ecología de Humedales, Estación Biológica de Doñana (EBD-CSIC), Seville, Spain. ${ }^{3}$ Centro de Investigación Biomédica en Red de Epidemiología y Salud Pública (CIBERESP), Madrid, Spain. ${ }^{4}$ Institute of Zoology, Slovak Academy of Sciences, Dúbravská cesta 9, SK-84506 Bratislava, Slovakia.

Received: 28 April 2018 Accepted: 5 September 2018

Published online: 01 October 2018

\section{References}

1. Borkent A. The biting midges, the Ceratopogonidae (Diptera). In: Marquardt WC, editor. Biology of Disease Vectors. 2nd ed. San Diego: Elsevier Academic Press; 2005. p. 113-26.

2. Carpenter S, Groschup MH, Garros C, Felippe-Bauer ML, Purse BV. Culicoides biting midges, arboviruses and public health in Europe. Antiviral Res. 2013; 100:102-13

3. Atkinson CT, Van Riper C. Pathogenicity and epizootiology of avian haematozoa: Plasmodium, Leucocytozoon and Haemoproteus. In: Loye JE, Zuk M, editors. Bird-Parasite Interactions: Ecology, Evolution, and Behaviour. London: Oxford University Press; 1991. p. 19-48.

4. Mellor PS, Boorman J, Baylis M. Culicoides biting midges: their role as arbovirus vectors. Annu Rev Entomol. 2000:45:307-40.

5. Mellor PS, Boorman J. The transmission and geographical spread of African horse sickness and bluetongue viruses. Ann Trop Med Parasitol. 1995:89:1-15.

6. Da Rosa JFT, de Souza WM, de Paula Pinheiro F, Figueiredo ML, Cardoso JF, Acrani GO, et al. Oropouche virus: clinical, epidemiological, and molecular aspects of a neglected Orthobunyavirus. Am J Trop Med Hyg. 2017;96: 1019-30.

7. Valkiūnas G. Avian Malaria Parasites and Other Haemosporidia. Boca Raton: CRC Press; 2005

8. Merino S, Moreno J, Sanz J J Arriero E. Are avian blood parasites pathogenic in the wild? A medication experiment in blue tits (Parus caeruleus). Proc $\mathrm{R}$ Soc Lond B Biol Sci. 2000:267:2507-10.

9. Marzal A, De Lope F, Navarro C, Møller AP. Malarial parasites decrease reproductive success: an experimental study in a passerine bird. Oecologia. 2005;142:541-5

10. Valkiūnas G, Zickus T, Shapoval AP, lezhova TA. Effect of Haemoproteus belopolskyi (Haemosporida: Haemoproteidae) on body mass of the blackcap Sylvia atricapilla. J Parasitol. 2006;92:1123-5.

11. Tomás G, Merino S, Moreno J, Morales J, Martínez-de la Puente J. Impact of blood parasites on immunoglobulin level and parental effort: a medication field experiment on a wild passerine. Funct Ecol. 2007:21:125-33.

12. Martínez-de la Puente J, Merino S, Tomás G, Moreno J, Morales J, Lobato E, et al. The blood parasite Haemoproteus reduces survival in a wild bird: a medication experiment. Biol Lett. 2010;6:663-5.

13. Asghar M, Hasselquist D, Bensch S. Are chronic avian haemosporidian infections costly in wild birds? J Avian Biol. 2011;42:530-7. 
14. Asghar M, Hasselquist D, Hansson B, Zehtindjiev P, Westerdahl H, Bensch S Hidden costs of infection: chronic malaria accelerates telomere degradation and senescence in wild birds. Science. 2015;347:436-8.

15. Hellgren O, Bensch S, Malmqvist B. Bird hosts, blood parasites and their vectors - associations uncovered by molecular analyses of blackfly blood meals. Mol Ecol. 2008;17:1605-13.

16. Ishtiaq F, Guillaumot L, Clegg SM, Phillimore AB, Black RA, Owens IPF, et al. Avian haematozoan parasites and their associations with mosquitoes across Southwest Pacific Islands. Mol Ecol. 2008;17:4545-55.

17. Kimura M, Darbro JM, Harrington LC. Avian malaria parasites share congeneric mosquito vectors. J Parasitol. 2010;96:144-51.

18. Martínez-de la Puente J, Martínez J, Rivero-de Aguilar J, Herrero J, Merino S. On the specificity of avian blood parasites: revealing specific and generalist relationships between haemosporidians and biting midges. Mol Ecol. 2011; 20:3275-87.

19. Njabo KY, Cornel AJ, Bonneaud C, Toffelmier E, Sehgal RNM, Valkiūnas G, et al. Nonspecific patterns of vector, host and avian malaria parasite associations in a central African rainforest. Mol Ecol. 2011;20:1049-61.

20. Santiago-Alarcon D, Palinauskas V, Schaefer HM. Diptera vectors of avian haemosporidian parasites: untangling parasite life cycles and their taxonomy. Biol Rev. 2012;87:928-64

21. Garnham PCC. Malaria Parasites and other Haemosporidia. Oxford: Blackwell Scientific Publications; 1966.

22. Martínez-de la Puente J, Figuerola J, Soriguer R. Fur or feather? Feeding preferences of species of Culicoides biting midges in Europe. Trends Parasitol. 2015;3:16-22.

23. Jamnback H. The Culicoides of New York State (Diptera: Ceratopogonidae). NY State Mus Sci Serv Bull. 1965;399:1-154.

24. Braverman $Y$, Hulley PE. The relationship between the numbers and distribution of some antennal and palpal sense organs and host preference in some Culicoides (Diptera: Ceratopogonidae) from southern Africa. J Med Entomol. 1979:15:419-24.

25. Augot D, Hadj-Henni L, Strutz SE, Slama D, Millot C, Depaquit J, et al. Association between host species choice and morphological characters of main sensory structures of Culicoides in the Palaeartic region. PeerJ. 2017:5:e3478.

26. Weitz B. Identification of blood meals of blood-sucking arthropods. Bull World Health Organ. 1956:15:473.

27. Braverman Y, Boreham PFL, Galum R. The origin of blood meals of female Culicoides pallidipennis trapped in a sheepfold in Israel. J Med Entomol. 1971;8:379-81

28. Nevill EM, Anderson D. Host preferences of Culicoides midges (Diptera: (eratopogonidae) in South Africa as determined by precipitin tests and light trap catches. Onderstepoort J Vet Res. 1972;39:147-52

29. Blackwell A, Mordue W. Identification of bloodmeals of the Scottish biting midge, Culicoides impunctatus, by indirect enzyme-linked immunosorbent assay (ELISA). Med Vet Entomol. 1994:8:20-4.

30. Blackwell A, Brown M, Mordue W. The use of an enhanced ELISA method for the identification of Culicoides bloodmeals in host-preference studies. Med Vet Entomol. 1995;9:214-8

31. Niare S, Berenger JM, Dieme C, Doumbo O, Raoult D, Parola P, et al. Identification of blood meal sources in the main African malaria mosquito vector by MALDI-TOF MS. Malar J. 2016:15:87.

32. Alcaide M, Rico C, Ruiz S, Soriguer R, Muñoz J, Figuerola J. Disentangling vector-borne transmission networks: a universal DNA barcoding method to identify vertebrate hosts from arthropod bloodmeals. PLoS One. 2009;4:e7092.

33. Van der Saag MR, Gu X, Ward MP, Kirkland PD. Development and evaluation of real-time PCR assays for bloodmeal identification in Culicoides midges. Med Vet Entomol. 2016;30:155-65.

34. Goffredo M, Buttigieg M, Meiswinkel R, Delécolle JC, Chircop S. Entomological surveillance for bluetongue on Malta: first report of Culicoides imicola Kieffer. Vet Ital. 2004:40:278-81.

35. Lysyk TJ. Abundance and species composition of Culicoides (Diptera: Ceratopogonidae) at cattle facilities in southern Alberta, Canada. J Med Entomol. 2006:43:840-9.

36. Casati S, Racloz V, Delécolle JC, Kuhn M, Mathis A, Griot C, et al. An investigation on the Culicoides species composition at seven sites in southern Switzerland. Med Vet Entomol. 2009;23:93-8.

37. Narladkar BW, Shivpuje PR. Prevalence, population dynamics and host preferences of Culicoides spp. (Diptera: Ceratopogonidae) of livestock in Marathwada region of Maharashtra State. Vet World. 2014;7:717-26.
38. Valera F, Carrillo CM, Barbosa A, Moreno E. Low prevalence of haematozoa in Trumpeter finches Bucanetes githagineus from south-eastern Spain: additional support for a restricted distribution of blood parasites in arid lands. J Arid Environ. 2003:55:209-13.

39. Václav R, Betáková T, Švančarová P, Pérez-Serrano J, Criado-Fornelio Á, Škorvanová L, et al. Nest ecology of blood parasites in the European roller and its ectoparasitic carnid fly. Exp Parasitol. 2016;165:71-80.

40. Alarcón-Elbal PM, Lucientes J. Actualización del catálogo de Culicoides Latreille, 1809 (Diptera, Ceratopogonidae) de España. Graellsia. 2012;68:353-62.

41. Estrada R, Carmona VJ, Alarcón-Elbal PM, Miranda MA, Borrás D, Roche ML, et al. Primera cita de Culicoides paolae Boorman, 1996 (Diptera, Ceratopogonidae) para la Península Ibérica. Bol SEA. 2011;49:217-21.

42. Boorman J, Mellor PS, Scaramozzino P. A new species of Culicoides (Diptera, Ceratopogonidae) from southern Italy. Parassitologia. 1996;38:501-3.

43. Barceló C, Miranda MA. Bionomics of livestock-associated Culicoides (biting midge) bluetongue virus vectors under laboratory conditions. Med Vet Entomol. 2017; https://doi.org/10.1111/mve.12286.

44. Meiswinkel R, Labuschagne K, Goffredo M. Christopher Columbus and Culicoides: was C. jamaicensis Edwards, 1922 introduced into the Mediterranean 500 years ago and later re-named C. paolae Boorman 1996? Vet Ital. 2004;40:340-4.

45. Černý O, Votýpka J, Svobodová M. Spatial feeding preferences of ornithophilic mosquitoes, blackflies and biting midges. Med Vet Entomol. 2011;25:104-8.

46. Ferraguti M, Martínez-de la Puente J, Ruiz S, Soriguer R, Figuerola J. On the study of the transmission networks of blood parasites from SW Spain: diversity of avian haemosporidians in the biting midge Culicoides circumscriptus and wild birds. Parasit Vectors. 2013;6:208.

47. Lázaro R, Rodríguez-Tamayo ML, Ordiales R, Puigdefábregas J. El clima. In: Mota J, Cabello J, Cerrillo Ml, Rodríguez-Tamayo ML, editors. Subdesiertos de Almería: naturaleza de cine. Murcia: Consejería de Medio Ambiente, Junta de Andalucía; 2004. p. 63-79.

48. Lázaro R, Rodrigo FS, Gutiérrez L, Domingo F, Puigdefábregas J. Analysis of a thirty-year rainfall record (1967-1997) from semi-arid SE Spain: a plant ecological perspective. J Arid Environ. 2001;48:373-95.

49. Valera F, Václav R, Calero-Torralbo MA, Martínez T, Veiga J. Natural cavity restoration as an alternative to nest box supplementation. Restor Ecol. 2018; https://doi.org/10.1111/rec.12841.

50. Václav R, Valera F, Martínez T. Social information in nest colonisation and occupancy in a long-lived, solitary breeding bird. Oecologia. 2011;165:617-27.

51. Avilés JM, Sánchez JM, Sánchez A, Parejo D. Breeding biology of Roller Coracias garrulus L. 1758 in farming areas of the southwest of the Iberian Peninsula. Bird Study. 1999;46:217-23.

52. Cramp S. Handbook of the Birds of Europe the Middle East and North Africa: the Birds of the Western Palearctic, Vol. IV. Terns to Woodpeckers. Oxford: Oxford University Press; 1985.

53. Tomás G, Merino S, Martínez-de la Puente J, Moreno J, Morales J, Lobato E. A simple trapping method to estimate abundances of blood-sucking flying insects in avian nests. Anim Behav. 2008:75:723-9.

54. González M, Alarcón-Elbal PM, Valle-Mora J, Goldarazena A. Comparison of different light sources for trapping Culicoides biting midges, mosquitoes and other dipterans. Vet Parasitol. 2016;226:44-9.

55. McDermott EG, Mullens BA. The dark side of light traps. J Med Entomol. 2018;55:251-61.

56. González M, Goldarazena A. El género Culicoides en el País Vasco. Guía Práctica para su identificación y control. Vitoria-Gasteiz, España: Servicio Central de Publicaciones del Gobierno Vasco; 2011.

57. Mathieu B, Cêtre-Sossah C, Garros C, Chavernac D, Balenghien T, Carpenter $\mathrm{S}$, et al. Development and validation of IIKC: an interactive identification key for Culicoides (Diptera: Ceratopogonidae) females from the Western Palaearctic region. Parasit Vectors. 2012;5:137.

58. Dyce AL. The recognition of nulliparous and parous Culicoides (Diptera: Ceratopogonidae) without dissection. Aus J Ent. 1969;8:11-5.

59. Gutiérrez-López R, Martínez-de la Puente J, Gangoso L, Soriguer RC, Figuerola J. Comparison of manual and semi-automatic DNA extraction protocols for the barcoding characterization of hematophagous louse flies (Diptera: Hippoboscidae). J Vector Ecol. 2015;40:11-5

60. Hellgren O, Waldenström J, Bensch S. A new PCR assay for simultaneous studies of Leucocytozoon, Plasmodium, and Haemoproteus from avian blood. J Parasitol. 2004;90:797-802.

61. McClintock BT, Nichols JD, Bailey LL, Mackenzie DI, Kendall W, Franklin AB. Seeking a second opinion: uncertainty in disease ecology. Ecol Lett. 2010;13:659-74 
62. Bensch S, Hellgren O, Pérez-Tris J. MalAvi: a public database of malaria parasites and related haemosporidians in avian hosts based on mitochondrial cytochrome b lineages. Mol Ecol Res. 2009;9:1353-8.

63. Sergeant ESG. Epitools epidemiological calculators. Ausvet Pty Ltd. 2018; http://epitools.ausvet.com.au. Accessed 18 Apr 2018

64. R Core Team. R: A language and environment for statistical computing. Vienna: R Foundation for Statistical Computing; 2015.

65. Fox J. Effect displays in R for generalised linear models. J Stat Softw. 2003;8:1-27.

66. Bates $D$, Mächler M, Bolker B, Walker S. Fitting linear mixed-effects models using Ime4. J Stat Softw. 2015;67:1-48.

67. Ortega MD, Mellor PS, Rawlings O, Pro MJ. The seasonal and geographical distribution of Culicoides imicola, C. pulicaris group and C. obsoletus group biting midges in central and southern Spain. Arch Virol. 1998;14:85-91.

68. Ventura D, Pagès N, Sarto V. Citas nuevas e interesantes de Culicoides Latreille, 1809 para Cataluña y la Península Ibérica (Diptera, Nematocera, Ceratopogonidae). Bol Asoc Esp Entomol. 2005;29:75-86.

69. Martínez-de la Puente J, Merino S, Tomás G, Moreno J, Morales J, Lobato E, et al. Factors affecting Culicoides species composition and abundance in avian nests. Parasitology. 2009;136:1033-41.

70. Del Río R. Estrategias de control y competencia vectorial de las especies de Culicoides vectores del virus de la lengua azul en península Ibérica y Baleares, PhD Thesis. Palma de Mallorca: Universitat de les Illes Balears; 2012.

71. Estrada R, Alarcón-Elbal PM, Carmona Salido VJ, Ruiz Arrondo I, Delacour S, Pinal R, et al. Culicoides (Diptera, Cerotopogonidae) de Aragón. Bol SEA. 2013;53:153-60

72. Alarcón-Elbal PM, Estrada R, Carmona-Salido VJ, Calvete C, Lucientes J. Composición faunística y dinámica poblacional de los Culicoides (Diptera: (eratopogonidae) de Castilla-La Mancha. An Biol. 2016;28:37-61.

73. Augot D, Mathieu B, Hadj-Henni L, Barriel V, Mena SZ, Smolis S, et al. Molecular phylogeny of 42 species of Culicoides (Diptera, Ceratopogonidae) from three continents. Parasite. 2017;24:23.

74. Slama D, Haouas N, Mezhoud H, Babba H, Chaker E. Blood meal analysis of Culicoides (Diptera: Ceratopogonidae) in central Tunisia. PLoS One. 2015;10: e0120528.

75. Foxi C, Pinna M, Monteys VSI, Delrio G. An updated checklist of the Culicoides Latreille (Diptera: Ceratopogonidae) of Sardinia (Italy), and seasonality in proven and potential vectors for bluetongue virus (BTV). Proc Entomol Soc Wash. 2011;113:403-16.

76. Votýpka J, Synek P, Svobodova M. Endophagy of biting midges attacking cavity-nesting birds. Med Vet Entomol. 2009;23:277-80.

77. Pettersson E, Bensch S, Ander M, Chirico J, Sigvald R, Ignell R. Molecular identification of blood meals and species composition in Culicoides biting midges. Med Vet Entomol. 2013;27:104-12.

78. Malmqvist B, Strasevicius D, Hellgren O, Adler PH, Bensch S. Vertebrate host specificity of wild-caught blackflies revealed by mitochondrial DNA in blood. Proc R Soc Lond B Biol Sci. 2004;271:152-5.

79. Santiago-Alarcon D, Havelka P, Schaefer HM, Segelbacher G. Bloodmeal analysis reveals avian Plasmodium infections and broad host preferences of Culicoides (Diptera: Ceratopogonidae) vectors. PLoS One. 2012;7:e31098.

80. Santiago-Alarcon D, Havelka P, Pineda E, Segelbacher G, Schaefer H. Urban forests as hubs for novel zoonosis: Blood meal analysis, seasonal variation in Culicoides (Diptera: Ceratopogonidae) vectors, and avian haemosporidians. Parasitology. 2013;140:1799-810.

81. Lassen SB, Nielsen SA, Kristensen M. Identity and diversity of blood meal hosts of biting midges (Diptera: Ceratopogonidae: Culicoides Latreille) in Denmark. Parasit Vectors. 2012;5:143.

82. Bobeva A, Zehtindjiev P, Ilieva M, Dimitrov D, Mathis A, Bensch S. Host preferences of ornithophilic biting midges of the genus Culicoides in the eastern Balkans. Med Vet Entomol. 2015;29:290-6.

83. Valkiūnas $\mathrm{G}$. Haemosporidian vector research: marriage of molecular and microscopical approaches is essential. Mol Ecol. 2011;20:3084-6.

84. Valkiūnas $G$, Kazlauskienė R, Bernotienė R, Palinauskas V, lezhova TA. Abortive long-lasting sporogony of two Haemoproteus species (Haemosporida, Haemoproteidae) in the mosquito Ochlerotatus cantans with perspectives on haemosporidian vector research. Parasitol Res. 2013; 112:2159-69.

85. Drovetski SV, Aghayan SA, Mata VA, Lopes RJ, Mode NA, Harvey JA, et al. Does the niche breadth or trade-off hypothesis explain the abundance-occupancy relationship in avian haemosporidia? Mol Ecol. 2014;23:3322-9.
86. Dimitrov D, Zehtindjiev P, Bensch S. Genetic diversity of avian blood parasites in SE Europe: cytochrome $b$ lineages of the genera Plasmodium and Haemoproteus (Haemosporida) from Bulgaria. Acta Parasitol. 2010;55:201-9.

87. Synek P, Popelková A, Koubínová D, Štastný K, Langrová I, Votýpka J, et al. Haemosporidian infections in the Tengmalm's Owl (Aegolius funereus) and potential insect vectors of their transmission. Parasitol Res. 2016;115:291-8.

88. Shurulinkov P, Golemansky V. Haemoproteids (Haemosporida: Haemoproteidae) of wild birds in Bulgaria. Acta Protozool. 2002;41:359-74.

89. Valkiūnas G, lezhova T. Parasitic Protozoa of the blood of birds in the USSR. 6. Haemoproteidae of columbiformes and coraciiformes. Ekologija. 1990;2: 86-103 (In Russian).

90. Cleaveland S, Laurenson MK, Taylor LH. Diseases of humans and their domestic mammals: pathogen characteristics, host range and the risk of emergence. Philos Trans R Soc Lond B Biol Sci. 2001:356:991-9.

91. Atkinson CT, Thomas NJ, Hunter DB. Parasitic Diseases of Wild Birds. Ames: Wiley-Blackwell; 2008.

\section{Ready to submit your research? Choose BMC and benefit from:}

- fast, convenient online submission

- thorough peer review by experienced researchers in your field

- rapid publication on acceptance

- support for research data, including large and complex data types

- gold Open Access which fosters wider collaboration and increased citations

- maximum visibility for your research: over 100M website views per year

At BMC, research is always in progress.

Learn more biomedcentral.com/submissions 